\title{
Components Acquaintance of Fuel Oil System Using Virtual Reality Application
}

\author{
Hari Prastowo ${ }^{1}$, Trika Pitana ${ }^{2}$, Gusti Ngurah Putu Wibhu Ary Martha ${ }^{3}$ \\ (Received: 28 August 2020 / Revised: 15 December 2020 / Accepted: 20 December 2020)
}

\begin{abstract}
Indonesia is known as the biggest archipelagic nation on the planet and is between two significant seas. In a roundabout way, Indonesia has tremendous regional water when contrasted and the land territory itself. With this, obviously, it tends to be said that Indonesia has colossal potential in the oceanic area, particularly since the Indonesian sea domain has consistently been a worldwide transportation path. This potential should be used ideally by this country, considering the mechanical advancement in Indonesia itself can be supposed to be very quick. Innovation that is utilized carefully and applied to the sea world can give Indonesia benefits for a few areas, for example, the economy, industry, and even schooling. Innovation that can be used in the oceanic world, particularly in the field of transportation is PC illustrations innovation, which in its application can be utilized during the time spent to plan, fix and support, reproductions and preparing for training and others with the 3D display. Virtual Reality (VR) is a counterfeit world or can be said as a computerized world where everything in there is the consequence of representation made utilizing $3 \mathrm{D}$ innovation from the PC. Virtual Reality permits us to cooperate and encounter encounters that are practically like this present reality. The reason for this exploration or the last task is to use innovation that is growing quickly well in the learning cycle in the oceanic world. With Virtual Reality, it is conceivable to make new learning strategies for training, particularly in the presentation of segments of the fuel oil framework on the ship. Because of a few restrictions confronted when mentioning direct objective facts to the ship, including authorization or admittance to enter the ship, time is restricted. Along these lines, it is normal that utilizing Virtual Reality can help the learning cycle for training by making an application that can be utilized in perceiving and understanding the segments of the fuel oil framework on a ship.
\end{abstract}

Keywords — 3D modeling, education, fuel oil system, virtual reality.

\section{INTRODUCTION}

$\mathrm{T}$ echnology, business, education, and everything in this era experienced very rapid development and progress when compared to previous years. Everything is demanded to be able to meet all the necessities needed by humans in supporting all activities for the continuation of human beings themselves. It is undeniable, technology is one thing that is very supportive of the continuity of human life today because with technology all things can be easy both in the industrial, economic, and educational sectors.

Indonesia is known as the biggest archipelagic nation on the planet and is between two significant seas. In a roundabout way, Indonesia has immense regional water when contrasted and the land zone itself. With this, obviously, it very well may be said that Indonesia has gigantic potential in the sea area, particularly since the Indonesian oceanic region has consistently been a global delivery path. This potential should be used ideally by this country, considering the mechanical advancement in Indonesia itself can be supposed to be very fast. Innovation that is utilized shrewdly and applied to the oceanic world can furnish Indonesia with benefits for a

${ }_{1}$ Hari Prastowo, Department of Marine Engineering, Institut Teknologi Sepuluh Nopember, Surabaya 60111, Indonesia, Email: hprastowo@its.ac.id

2Trika Pitana, Department of Marine Engineering, Institut Teknologi Sepuluh Nopember, Surabaya 60111, Indonesia, Email: trika@ne.its.ac.id

3Gusti Ngurah Putu Wibhu Ary Martha, Institut Teknologi Sepuluh Nopember, Surabaya 60111, Indonesia, Email: ngurahwibhu12@gmail.com few areas, for example, the economy, industry, and even schooling. Innovation that can be used in the oceanic world, particularly in the field of transportation is PC illustrations innovation, which in its application can be utilized during the time spent to plan, fix and support, reproductions and preparing for instruction and others with 3D displaying through a framework known as Virtual Reality and Augmented Reality.

Virtual Reality is not a technology that has only recently been discovered. VR is a way for humans to visualize, manipulate, and interact with computers and extremely complex data [1]. The user can interact with the world and directly manipulate the objects within the world. VR creates a simulation of the real-life situation [2]. Virtual Reality has been around and developed since the 1960s. Virtual Reality has a concept that allows its users to interact with the virtual environment, or it can be said that the environment is approaching real conditions. From the 1960s until now, of course, Virtual Reality has experienced many developments. In its application, Virtual Reality is currently very influential in the learning process, and even practice in the world of medical education, sciences, archeology, history, physics, and engineering by creating a computer-based virtual learning environment (VLE). Current education regularly requires an understudy to fathom unpredictable or conceptual ideas or acknowledge situations and circumstances that at this point don't exist. To this end, regular systems for training dynamic ideas are the utilization of allegory and relationship, particularly inside technical disciplines. By utilizing a similarity we portray an occasion or unique idea regarding regularly perceptible reality.

The thought behind VR is to convey a feeling of being, in this manner giving, in any event, the eye what it 
would have gotten on the off chance that it was there and, more significant, to have the picture change immediately as the perspective is changed [3]. The view of spatial truth is driven by different obvious signs, similar to relative size, splendor, and rakish development. One of the most grounded is a viewpoint, which is especially incredible in its binocular structure in that the privilege and left eyes see various pictures. Intertwining these pictures into one 3D discernment is the premise of stereovision. The information on profundity gave by each eye seeing a marginally extraordinary picture, eye parallax is best for objects close to you. Articles farther away basically cast a similar picture on each eye. The common clothing regulation for VR is a protective cap with goggle-like showcases, one for each eye. Each show conveys a somewhat alternate point of view picture of what you would check whether you were there. As you move your head, the picture quickly refreshes with the goal that you believe you are rolling out these improvements by moving your head (versus the PC following your development, which it is). You think you are the reason, not the impact.

That is, we relate concepts to experience. The experience provides the material for the construction of a mental model of the concept, which in turn leads to the foundation of knowledge [4]. Technology from Virtual Reality has been used or applied for psychological rehabilitation, construction, manufacturing, tourism, forensic psychiatry, and other fields. Because basically, humans will learn more from experience. The experiential nature of VR supports a constructivist approach to learning [5].

Specialists in the field have commonly concurred that VR innovation is energizing and can give an interesting and compelling approach to learn and that VR ventures are exceptionally rousing to students [6]. Making their own virtual universes has been appeared to empower a few understudies to dominate content and to extend their comprehension of what they have realized [7]. This preferred position of the innovation has been referred to by engineers and analysts from such different fields as firefighting, against illegal intimidation preparing, atomic decommissioning, crane driving and security, airplane investigation and support, car splash painting, and the person on foot wellbeing for youngsters [7]. In the business, VR has demonstrated to be a powerful instrument for aiding laborers assesses item plans. In 1999, BMW investigated the capacity of VR for checking item plans [8].

In the shipping world, as a student, it is crucial to know and understand every system and equipment or components on a ship, especially on the machinery system that can be said to be a vital organ of a ship. Conducting learning or observing the ship directly is a very good thing and will be very helpful to better understand the machinery system contained in the engine room of the ship because a real visual understanding will be easier to understand if compared to just getting a verbal understanding without ever see the real situation and condition of what is learned. Conducting direct observation on the ship is certainly not that easy because we have to consider several aspects, including permission to get access to the ship, especially to the engine room, the availability of time from the students themselves, and others. This case can be overcome, of course, by applying the technology of Virtual Reality as mentioned earlier.

It is expected that the implementation of Virtual Reality in this field, which as a new learning method can help users to understand while providing experience about components acquaintance of fuel oil system on ship rooms that can be accessed anytime and anywhere.

\section{METHODOLOGY}




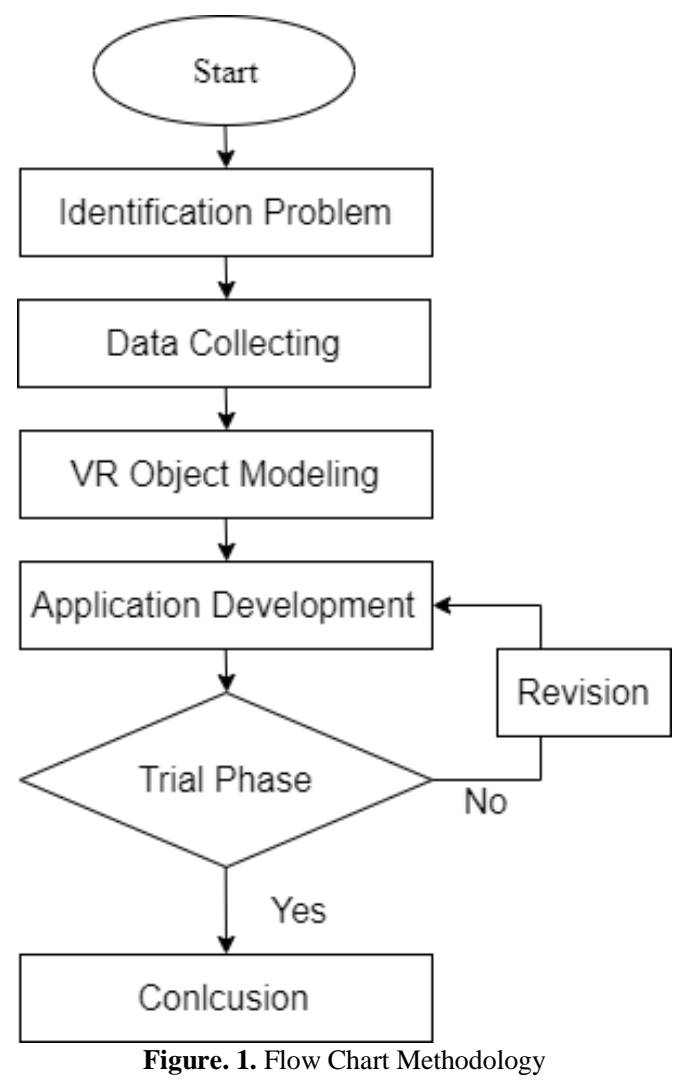

\section{A. Identification Problem}

Problem identification is a step taken in analyzing the problems that might arise during this final project. As for some obstacles that might arise during the survey that is, it might have difficulty in determining the schedule related to shipping the ship itself. Then the second is in the process of working on the $3 \mathrm{D}$ design of the conditions on the ship which may be a little difficult to really visualize according to the real situation in the room to be observed.

B. Data Collecting

Data collecting is a step taken in collecting data related to the needs of the final project. In this step, the data needed is the location of each component on the ship and an overview of the room. In addition, information about how many components and how they work is also very much needed in explaining the components that exist and will be visualized in $3 \mathrm{D}$. The data will be collecting from MV. Meratus Benoa is:

1. General data of MV. Meratus Benoa

2. Location of each equipment and the amount of each equipment of the fuel oil system

3. Engine room layout of MV. Meratus Benoa

MV. Meratus Benoa is a container ship owned by PT. Meratus Line was built in China in 2011. MV. Meratus Benoa has an overall length (length) of 106.68 meters and a width of 20.6 meters.



Figure. 2. MV. Meratus Benoa

C. Virtual Reality Object Modelling

Object modeling is a step to design of Fuel Oil System equipment 3D model that consists of components in the Fuel Oil System model. It is done by analyzing the data obtained from the survey that has been conducted. By comparing and sorting the data, then will be obtained the final 3D model of Fuel Oil System components along with the location and its information. The 3D model will be drawn in Blender 3D and Rhinoceros 3D which is a free and open-source 3D computer graphics software used for creating 3D models, visual effects, 3D interactive application, etc. The model will be finalized as close as the actual object. After the final 3D rendered, the model will be added to Autodesk VRED. 


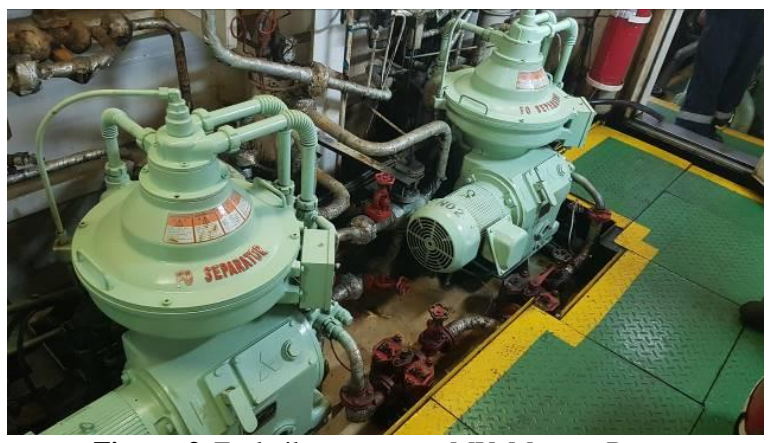

Figure. 3. Fuel oil separator on MV. Meratus Benoa

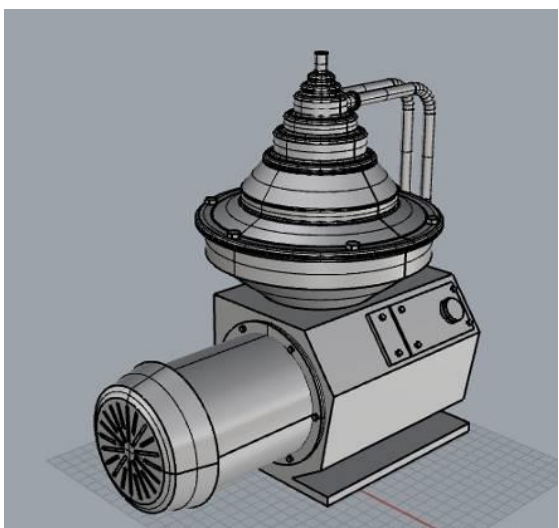

Figure. 4. 3D of fuel oil separator

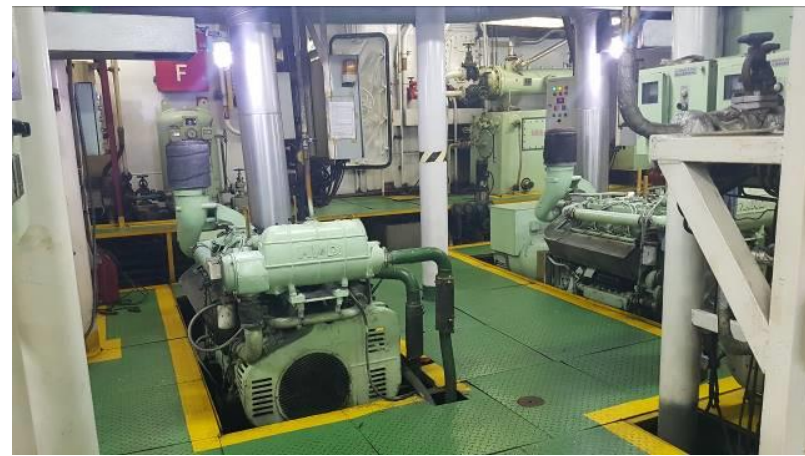

Figure. 5. Engine Room of MV. Meratus Benoa

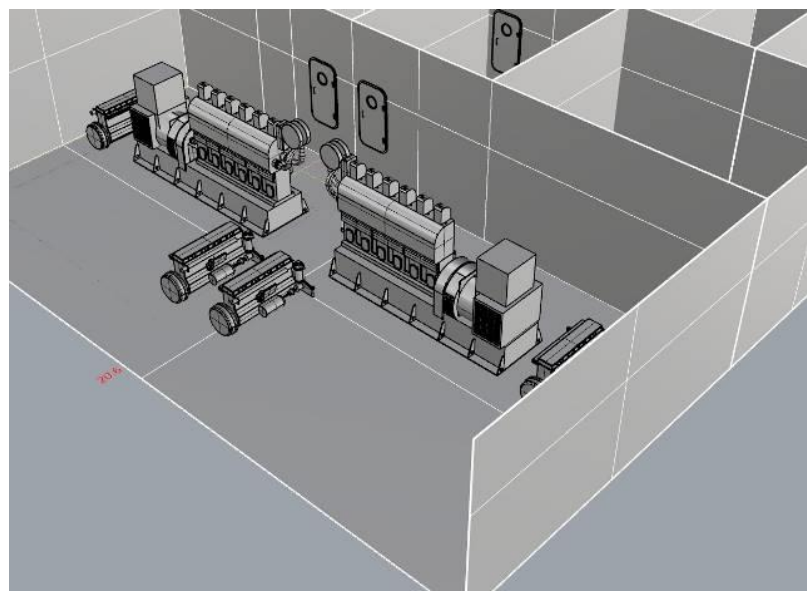

Figure. 6. Arrange the components

D. Application Development

Application Development is the step after the modeling is complete which will later be included in the android application or computer application.

E. Trial

In the trial phase, applications that have been developed will then be tested on ten users to find out various weaknesses and strengths of Virtual Reality. Furthermore, the weaknesses of the product will be evaluated for further development.

F. Conclusion

The last stage is the conclusion. After testing ten 
users and felt that the virtual reality that was developed was sufficient, then a report will be made on the development of this Virtual Reality application which is used as a learning media for education in the introduction of components in the Fuel Oil System.

\section{RESULTS AND DISCUSSION}

A. Virtual Reality Development Process

Basically, virtual reality (VR) is an artificial world or can be said as a digital world where everything in there is the result of visualization created using 3D technology from the computer, so $3 \mathrm{D}$ objects and the

TABLE 1.

GENERAL DATA OF MV. MERATUS BENOA

\begin{tabular}{l}
\hline Ghip Name \\
Type of Ship \\
Call Sign \\
Flag / Port of Registry \\
Owner \\
Classification \\
Official Number \\
IMO Number \\
Build \\
Gross Tonnage (GT) \\
Net Tonnage (NT) \\
Summer / Tropical \\
Deadweight \\
Length Overall x \\
Breadth Extreme \\
Summer / Tropical \\
Draught \\
Service speed \\
Fuel Oil Consumption \\
Container Capacity \\
Fuel Oil Capacity \\
\hline
\end{tabular}

2. Pipe Instruments and Diagram of MV. Meratus Benoa to determine the amount of fuel oil system equipment.

3. Engine Room Layout of MV. Meratus Benoa to determine every room on a ship.

4. Photo of fuel oil system equipment to determine the location.

The process of making VR starts from preparing the material in the form of a 3D model of each component which will be inputted into the VR software (VRED). Making 3D Modeling can use 3D software such as a blender, AutoCAD, Solid, Catia, Rhino. For the software used for VR, the ship itself uses a combination of Blender and Rhino. Blender for the manufacture of the components of the ship as shown in Figure 4, and Rhino to make the room and set up the placement of each environment in this virtual reality application is made based on previously obtained data so that later users can interact and get experiences as similar as possible to conditions in the real world. The data that has been obtained is:

1. General data or information from MV. Meratus Benoa as shown in table 1 . The information referred to includes the workings of the fuel oil system on the ship itself, the room of the fuel oil system.

Meratus Benoa
Container Deck Ship
PNPC
Indonesia / Surabaya
Meratus Line
BKI \& NK
$2010 \mathrm{Ka}$ No. 4282/L
9509231
China, 2010
$3668 \mathrm{~T}$
$1100 \mathrm{~T}$
5161 / 5349 Tons
$106.68 \mathrm{~m} \times 20.6 \mathrm{~m}$
$4.350 \mathrm{~m}$
$11.5 \mathrm{kn}$ (loading
condition)
$13 \mathrm{KL} / \mathrm{Day}$ HFO
$368 \mathrm{TEUS} / 64 \mathrm{FEUS}$
$575 \mathrm{~m}{ }^{2}$

component as shown in Figure 6. After the Modeling is complete, the file is saved in the form of a .obj file which will later be entered into the VRED software which is software that supports VR. The first time that is done when the file has been entered into the VRED software is to give color to each component or space of the ship, or what is commonly called the color rendering process. The choice of color and texture is adjusted in such a way as to its real condition so that when it is tested using VR, it can produce maximum objects.

After all the 3D objects are arranged in the VRED program, the next step is to create a display for the user interface for the virtual reality application later. The appearance of the user interface is made as attractive as possible and easy to use. 


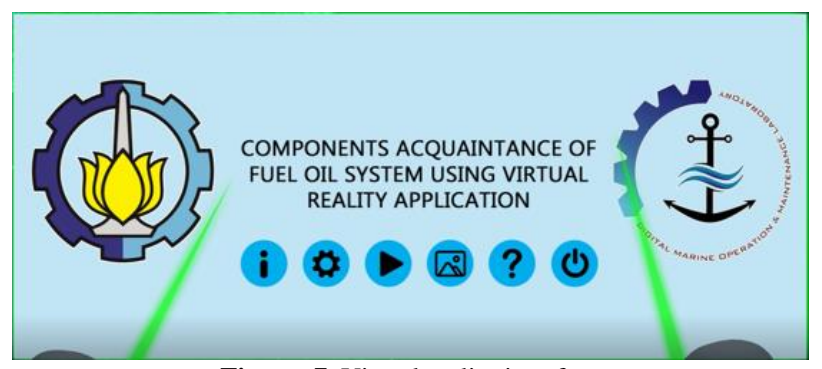

Figure. 7. Virtual reality interface

In the user interface, as shown in figure 6 , several buttons have different functions. On the user interface, there is an "information" button that contains information from the application developer, as shown in Figure 7. After that, there is a "settings" button where the user can set the features of the virtual reality application later. Then there is a "play" button that allows users to use virtual reality applications directly. After that, there is a button "image gallery" which contains the photos from the MV. Meratus Benoa. The last two buttons are "help" which will provide information on how to operate the virtual reality application, and the "power" button which helps the user to turn off the virtual reality application when finished using it.

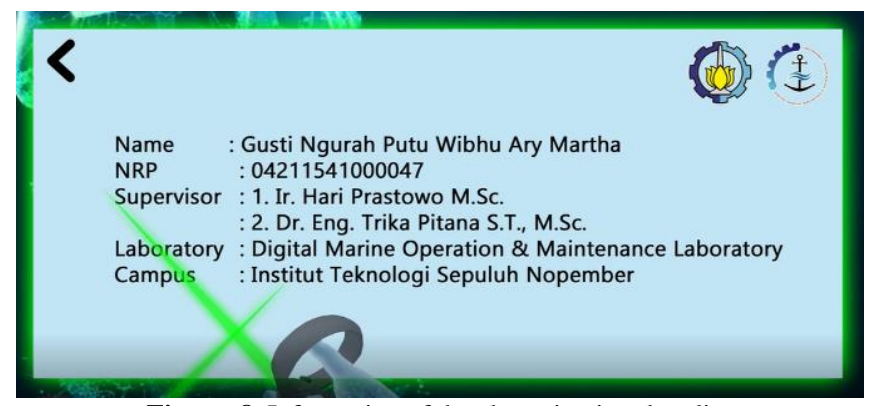

Figure. 8. Information of developer in virtual reality

Three rooms will be visualized in 3D. In each room, there are components of the fuel oil system that have different functions. Information regarding the function of each component was previously collected during the data collecting process. The number of components is also adjusted as much as possible to the actual number of components contained on the MV. Meratus Benoa. The rooms to be visualized are the storage room, engine room, and purifier room, as shown in Figure 9.

Information about each component of the fuel oil system on the ship can be seen if the user must point the pointer towards a particular component when going to a room. For example, if the user goes to the "purifier room", the user points the pointer towards the heater. Information about the heater's function will appear immediately as shown in Figure 10, as well as if it is done to other components.

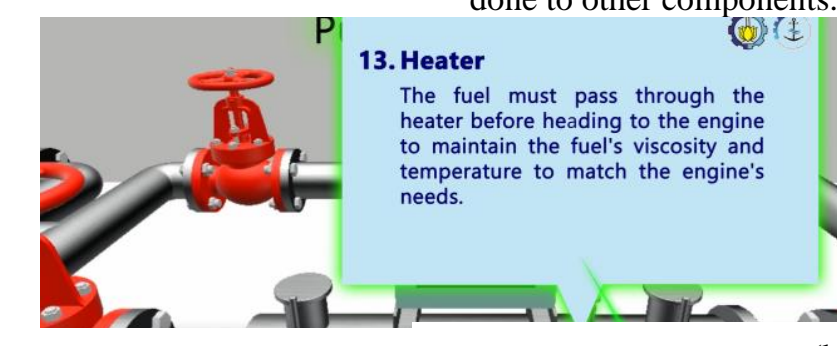

(a)

\section{B. Questionnaire}

The purpose of this questionnaire itself is to find out several things related to virtual reality applications, including:

1. Whether this virtual reality application interesting enough or not?
L. wnetner tnıs virtual reaııty appııcation neıps in knowing and understanding the fuel oil system and its components on a ship or not.

3. Are there any deficiencies in this virtual reality application so that it can be developed and be better in the future? 


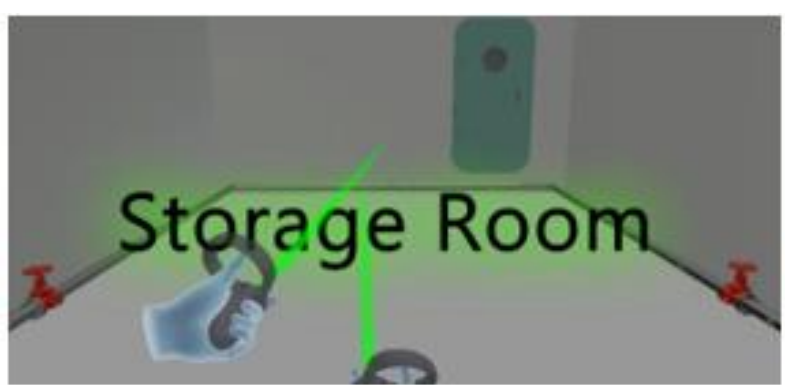

(a)

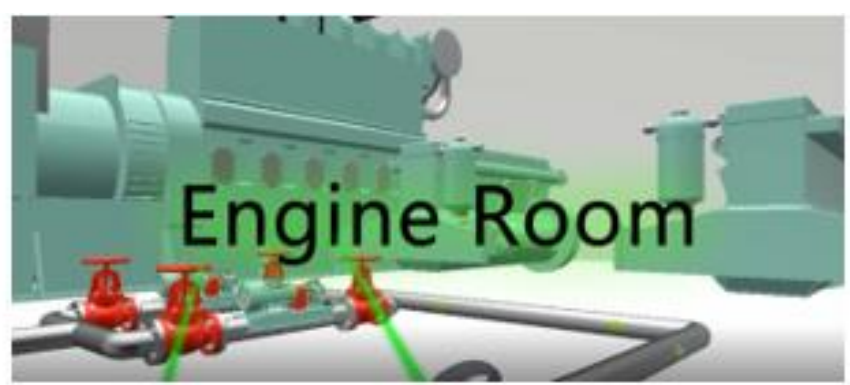

(b)

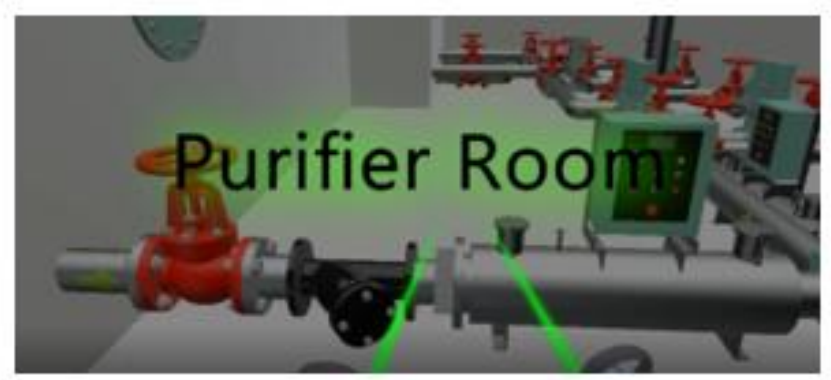

(c)

Figure 6 (a) Storage room in virtual reality, (b) Engine room in virtual reality, (c) Purifier room in virtual reality.

The questionnaire will be distributed to several people after the virtual reality application is completed. After several people try this virtual reality application, these

respondents will be given a questionnaire to conduct an assessment related to the virtual reality application that has been developed.

Due to the covid-19 pandemic, it is impossible to
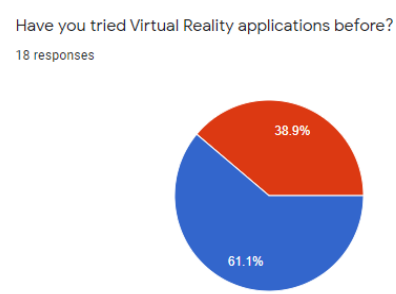

Figure. 11. Chart result of question number 1

Figure 11 shows a chart obtained from distributing questionnaires to several people. 18 people have filled out questionnaires and watched the virtual reality application demo video. Out of 18 people, $61.1 \%$ said that they had never heard of or understood a fuel oil distribute questionnaires and trial virtual reality applications directly. So, the distribution of virtual reality application questionnaires and trials can only be done online by distributing the questionnaire and the virtual reality application trial demo video. The following are some of the charts obtained based on distributed questionnaires:

1. Have you tried virtual reality before?

$$
\bullet \text { Yes }
$$

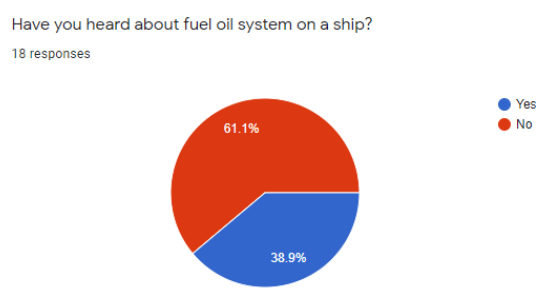

Figure. 12. Chart result of question number 2

Figure 12 shows a chart obtained from distributing questionnaires to several people. The chart above shows how many people have heard or known about the fuel oil system on ships. This question arose before the virtual reality app demo video was played. As a result, $61.1 \%$ of system, while $38.9 \%$ of 18 people said that they had heard or understood fuel oil systems.

2. Have you heard about the fuel oil system on a ship? the 18 people said they had never heard of or knew about ships' fuel oil system. This can happen because the questionnaires were not only distributed to people in the marine engineering department. Meanwhile, $38.9 \%$ of 18 
people said they had heard about the fuel oil system on ships.
3. After seeing the demo video, how do you understand the fuel oil system on this ship? (Scale 1-5)

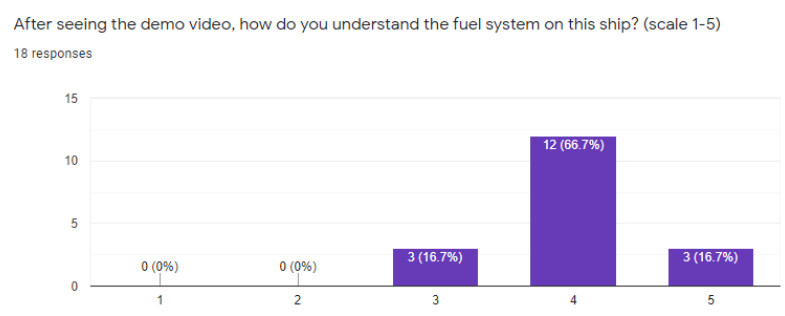

Figure. 13. Chart result of question number 3

Figure 13 shows the response of 18 people after watching the virtual reality application demo video. In question number 3 , use a scale from 1 to 5 to describe the respondent's understanding of the ship's fuel oil system components. The explanation for scale 1 is not understanding, scale 2 is not understanding enough, scale 3 is quite understanding, scale 4 understands, and scale 5 is very understanding. $16.7 \%$ of 18 people said they chose scale 3 , which means they are quite understood with the ships' fuel oil system. Furthermore, $66.7 \%$ of 18 chose scale 4, which means they understand the fuel oil system and its components, and $16.7 \%$ of 18 people chose scale 5, which means they were very understanding with the fuel oil system and its components.

4. After watching the demo video, does this virtual reality application help you in understanding the fuel oil system on MV. Meratus Benoa?

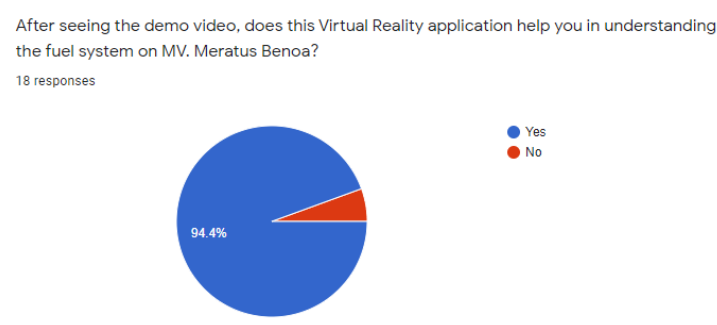

Figure. 14. Chart result of question number 4

Figure 14 shows the response of 18 people after watching the virtual reality application demo video. $94.4 \%$ of 18 people stated that this virtual reality application helped them understand the fuel oil system and its components. In comparison, 5.6\% said that this virtual reality application did not help them understand the fuel oil system.

5. How interesting do you think this virtual reality application is?

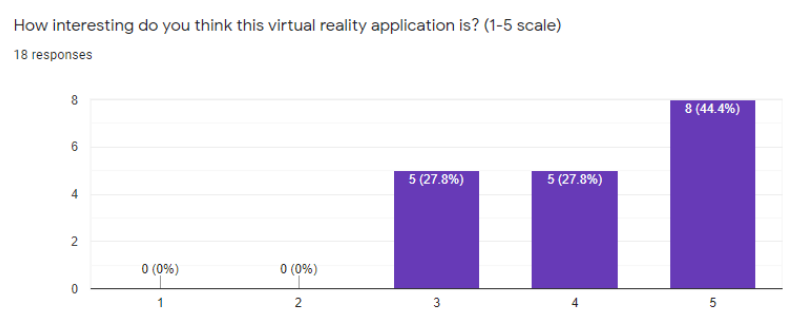

Figure. 15. Chart result of question number 5

Figure 15 shows a chart of how interesting virtual reality applications are about introducing fuel oil system components to ships using a scale of 1-5. The explanation of scale 1 is unattractive. Scale 2 is less attractive, scale 3 is interesting enough, scale 4 is interesting, and scale 5 is very interesting. From the questionnaires that have been distributed, $27.8 \%$ of 18 people said that this virtual reality application is quite interesting. Another $27.8 \%$ of people said that this application was interesting, and the last $44.4 \%$ of 18 people said that this application was very interesting.

\section{CONCLUSION}

In this thesis or final project, virtual reality is developed and designed to refer to MV. Meratus Benoa. The digital environment contained in virtual reality is designed based on the real condition of MV. Meratus Benoa. The components of the fuel oil system in virtual reality are also designed according to data obtained from the MV. Meratus Benoa.

This simulation in virtual reality application allows users to explore three rooms related to the fuel oil system. The first room is the HFO / fuel storage room, the second room is the engine room, and the last room is the purifier. There are components of the fuel oil system in each room and information or descriptions of each component's functions.

The simulation in this virtual reality application aims 
to help the learning process, especially regarding its fuel oil system. It is considering that not everyone has access to enter the ship.

\section{ACKNOWLEDGEMENTS}

The author thanks all lecturers and students of the Digital Marine Operation and Maintenance (DMOM) laboratory who have helped a lot during the work of this study.

\section{REFERENCES}

[1] Isdale, J. (1993). What is virtual reality? A homebrew introduction. Retrieved November 12, 2005. [Online]. Available: http://whatis.techtarget.com

[2] Haag, S.; Cummings, M., \& Dawkins, J. (1998). Management Information Systems for the Information Age. Irwin/McGraw Hill, ISBN 0-07-025465-6, New York.

[3] Smith, S. \&. Lee, S. (2004). A pilot study for integrating virtual reality into an introductory design and graphics course. Journal of Industrial Technology. 20(4)
[4] Duffy, T. M., \& Jonassen, D. H. (1992). Constructivism and the technology of instruction: A conversation. Hillsdale N.J.: Lawrence Erlbaum.

[5] Winn, W. (1993). A conceptual basis for educational applications of virtual reality (Technical Report TR-93-9). Seattle, Washington: Human Interface Technology Laboratory, University of Washington.

[6] Mantovani, F., Gaggiolo, A., Castelnuovo, G. \& Riva, G. (2003) Virtual reality training for health-care professionals. CyberPsychology and Behavior, 6(4), 389-395.

[7] Ausburn, L. J. \& Ausburn, F. B. (2004). Desktop virtual reality: A powerful new technology for teaching and research in industrial teacher education. Journal of Industrial Technical Education, Vol. 41, No.4, [Online], Available: http://scholar.lib.vt.edu/ejournals/JITE/v41n4/ausburn.html

[8] Gomes de Sa, A. \& Zachmann, G. (1999). Virtual reality as a tool for verification of assembly and maintenance processes. Computers and Graphics, 23, 389-403. 